\title{
Analytical Determination of Fuel Economy Characteristics of Earth-Moving Machines
}

\author{
Vladimir Zhulai ${ }^{1}$, Vitaly Tyunin ${ }^{1 *}$, Alex Shchiyenko ${ }^{1}$, and Alexander Krestnikov ${ }^{1}$ \\ ${ }^{1}$ Voronezh State Technical University, 84, 20 let Oktyabrya str., 84, Voronezh, 394006, Russia
}

\begin{abstract}
The article considers the problem of the analytical determination of the fuel economy performance of earth-moving machines by the example of the road grader. The values of the road grader fuel consumption when performing the technological operations have been obtained and analyzed. The fuel balance of the EMM in the traction mode is presented. The fuel balance of the motor grader when digging soil has been defined and analyzed.
\end{abstract}

\section{Introduction}

By fuel economy is understood the vehicle's ability to perform an operation with the minimal fuel consumption per hour or per unit volume of the products being manufactured, which is achieved by the optimization of the operation parameters $[1,2,3,4]$. The fuel costs constitute a significant part of the net cost of a production unit, and for some earth-moving machines (EMM) reach up to half of the machine-shifts net cost. Consequently, fuel efficiency is one of the basic operational properties of EMM. [5,6,7,8].

\section{Material, methods and calculation}

Improving the fuel economy data of machines will allow us to reduce not only the cost of production and to save energy, but also to improve the environment. Therefore, the rational and economical use of the fuel consumed by the EMM is an important task.

To solve this problem it is necessary: first, to develop a method for analytical determination of fuel consumption when performing the operations of the EMM working cycle, and second, to establish an analytical relationship between fuel consumption and the design parameters of the EMM.

As an example of the EMM, let us consider the grader, which is designed primarily for grading and planning in the construction of earthworks and for road maintenance, as well.

When constructing a section of the motor road subgrade by the earth cut out of the ditch, the fuel consumed by the motor grader $[9,10,11,12]$ is:

$$
G_{F L}=G_{F D I G}+G_{F M O V}+G_{F F I N}+G_{F T U R}, \mathrm{~kg}
$$

\footnotetext{
* Corresponding author: tuninvl@yandex.ru
} 
where $G_{F D I G}, G_{F M O V}, G_{F F I N}, G_{F T U R}$ - the consumption of fuel when digging soil, moving the soil, when finishing the subgrade and when turning around the road grader, respectively, $\mathrm{kg}$.

When digging soil, the fuel consumption is

$$
G_{F D I G}=G_{F 1} \frac{2 L}{v_{V 1 A V}} n_{D}, \mathrm{~kg}
$$

when moving the soil, it is

$$
G_{F M O V}=G_{F 2} \frac{2 L}{v_{V 2 A V}} n_{M}, \mathrm{~kg}
$$

when finishing the subgrade, it is

$$
G_{F F I N}=G_{F 3} \frac{2 L}{v_{V 3 A V}} n_{F}, \mathrm{~kg}
$$

when turning around the road grader, it is

$$
G_{F T U R}=G_{F 4} 2 t_{M O V}\left(n_{D}+n_{M}+n_{F}\right), \mathrm{kg}
$$

where $G_{F 1}, G_{F 2}, G_{F 3}, G_{F 4}$ - the hourly fuel consumption when digging the soil, moving the soil, when finishing the subgrade and turning around the road grader, respectively, $\mathrm{km} / \mathrm{h} ; L_{-}$ the length of the bank, km; $v_{V 1 A V}, v_{V 2 A V}, v_{V 3 A V}$ - the average actual speeds of the grader motion when digging soil, moving the soil, when finishing the subgrade, respectively, $\mathrm{km} / \mathrm{h} ; n_{D}, n_{M}$, $n_{F}$ - the number of the operations when digging soil, moving the soil, when finishing the subgrade, respectively; $t_{M O V}-$ the duration of one turn, $h$.

The hourly fuel consumption $G_{F i}$ and the actual speeds of movement $v_{V \mathrm{i} A V}$ during passes can be determined analytically $[9,10,11,12]$, based on the condition that the traction force $T_{i}$ must be greater than or equal to the resistance when digging, moving and finishing subgrade.

When digging the soil $n_{D}$, the number of the road grader passes is determined by $[9,10,11,12]$ :

$$
n_{D}=\frac{k_{O D} F}{2 S_{C S}},
$$

where $k_{O D}$ - the coefficient of overlapping passes of the road grader when digging the soil; $F$ - the cross-section area of the bank, $\mathrm{m}^{2} ; S_{C S}-$ the projection area of the chips of the soil in the plane perpendicular to the direction of the grader motion, $\mathrm{m}^{2}$.

When moving soil $n_{m}$, the number of passes is determined by $[9,10,11,12]$ :

$$
n_{M}=k_{O M} \frac{l_{0}}{l_{M}},
$$

where $k_{O M}$ - the coefficient of overlapping passes when moving the soil; $l_{0}$ - the average required earth moving (the distance between the centers of the cross section gravity of the reserve and half of the bank), $\mathrm{m} ; l_{M}$ - the moving soil in one operation, $\mathrm{m}$.

When finishing the subgrade $n_{0}$, the number of passes is determined by $[9,10,11,12]$ :

$$
n_{F}=(0,25 \ldots 0,35) n_{D} \text {. }
$$


So, having the value of the fuel consumption of $G_{F L}$ one can determine the average hourly fuel consumption of $G_{F H}$ and the average specific fuel consumption per $1 \mathrm{~m}^{3}$ of the developed and displaced soil $g_{s}$ :

$$
\begin{gathered}
G_{F H}=\frac{G_{F L}}{T_{C}} \mathrm{~kg} / \mathrm{h}, \\
g_{y}=\frac{G_{F L}}{L F} \mathrm{~kg} /\left(\mathrm{h} \cdot \mathrm{m}^{3}\right),
\end{gathered}
$$

where $T_{C}$ - the length of the time of the working cycle, h.

$$
T_{C}=L\left(\frac{n_{D}}{v_{V 1 A V}}+\frac{n_{M}}{v_{V 2 A V}}+\frac{n_{F}}{v_{V 3 A V}}\right)+2 t_{M O V}\left(n_{D}+n_{M}+n_{F}\right), \mathrm{h}
$$

In order to establish the analytical relationship between the fuel consumption and the design parameters of the motor grader it is necessary to consider the fuel balance of the road grader. The fuel balance will allow us to estimate the exact distribution of engine energy, obtained during the fuel combustion, to perform the main process, to estimate the losses in the various mechanisms of the machine and the interaction of the wheel mover with the support surface.

The fuel balance equation of the motor grader can be written as follows $[13,14,15]$ :

$$
G_{F}=G_{C L}+G_{M L}+G_{T L}+G_{T P}+G_{f}+G_{C S} \pm G_{h}+G_{j} .
$$

The left part of this equation shows the hourly engine fuel consumption, and the right side - components of the fuel consumed by the useful traction power for all types of power losses.

The amount of the fuel consumed by calorific losses in the engine is

$$
G_{C L}=\left(\frac{G_{T} h_{u}}{U}-N_{i}\right) g_{T S F},
$$

where $h_{u}-$ the lower fuel consumption heat, $\mathrm{kJ} / \mathrm{kg} ; U-$ the thermal equivalent, i.e. the amount of the heat equivalent to the engine power of $1 \mathrm{~kW}$ for 1 hour, $\mathrm{kJ} /(\mathrm{kW} \cdot \mathrm{h})[16,17,18]$; $N_{i}$-the indicated power of the internal combustion engine, $\mathrm{kW} ; g_{T S F}-$ the theoretical specific fuel consumption, $\mathrm{g} / \mathrm{kW} \cdot \mathrm{h}[19]$.

The amount of the fuel consumed by the mechanical losses in the engine is

$$
G_{M L}=\frac{p_{M L} V_{h} n i}{120} g_{T S F}
$$

where $p_{M L}-$ the pressure of the mechanical losses, $\operatorname{MPa}[16,17,18] ; V_{h}-$ the displacement of the internal combustion engine; $n$ - the frequency of the engine crankshaft rotation; $i$ - the number of cylinders.

The amount of the fuel consumed by the lost power in the transmission is

$$
G_{T L}=N_{e}\left(1-\eta_{E T}\right) g_{T S F},
$$

where $\eta_{E T}-$ the efficiency of the transmission.

The amount of the fuel consumed by getting the traction power is

$$
G_{T P}=T v_{V} g_{T S F},
$$

The amount of the fuel consumed by overcoming rolling resistance is 


$$
G_{f}=P_{f} v_{T} g_{T S F},
$$

where $P_{f}$ - the force of the rolling resistance of the wheels; $v_{T}$ - the theoretical (circumferential) speed of the wheel mover.

The amount of the fuel consumed by the slipping of the wheel mover is

$$
G_{C S}=T v_{C S} g_{T S F},
$$

where $v_{\delta}$ - the speed of the wheel mover slipping.

The amount of the fuel consumed by overcoming the land slope ("+" movement on the rise, "-" the motion under the slope) is

$$
G_{h}= \pm G v_{V} \sin \alpha g_{T S F},
$$

where $G$ - the force of the machine gravity; $\alpha$ - the inclination angle of the surface motion to the horizon.

The amount of the fuel consumed by overcoming the forces of inertia is

$$
G_{j}=\left(\frac{\chi G v_{D}}{g} \cdot \frac{d v_{D}}{d t}\right) g_{T S F},
$$

where $\chi$ - the coefficient considering the rotating masses, $g$ - the acceleration of the gravity, $g=9.81 \mathrm{~m} / \mathrm{s}^{2} ; d v_{D} / d t$ - the translational machine acceleration, "+"speeding up, ""braking.

The initial data for the calculation are: the DZ-122 road grader; the A-01MC engine diesel; mechanical transmission; the running equipment: $1 \times 2 \times 3$ wheel diagram, $14.00-20$ tires; ground surface is horizontal $\left(G_{h}=0\right)$; ground is cohesive, tight, and dry; the working conditions of the road grader are: the length of the bank section $L=0.5 \mathrm{~km}$, the duration of one turn $t_{M O V}=0.1 \mathrm{~h}$, the coefficient of overlapping the road grader passes when digging soil $k_{O D}=1.5 \ldots 1.7$, and the coefficient of overlapping the passes when moving soil $k_{O M}=1.15$, the average required moving of soil $l_{0}=12.5 \mathrm{~m}$, moving soil in one pass $l_{\mathrm{M}}=1.9 \mathrm{~m}$, the steadystate straight moving $\left(G_{j}=0\right)$.

\section{Results and discussion}

All the design formulas presented above have been implemented in the program performed in Mathcad, which allows us to determine the fuel consumption of the road grader when changing any parameter included in formulas (2)...(8). For example, Figure 1 shows the effect of the soil type on the fuel consumption of the road grader. With increase in the category of soil, the fuel consumed by the motor graders increases, this is due, primarily, to the increase in the coefficient of specific resistance of soil cutting.

The fuel consumption included in formula (1) may also be presented as a percentage of the total fuel consumption (Figure 2) and then be analyzed.

Figure 2 shows that the fuel consumption when the digging soil GFDIG is $39 \%$, when moving soil GFMOV $-19 \%$, when finishing the subgrade GFFIN is $9 \%$ and when turning around the motor grader GFTUR $-33 \%$. In the context of the fuel economy, the most expensive is the process of digging the soil, because of the greatest resistances. Digging soil is performed at the mode of the maximum traction power, when the fuel consumption is also increased, besides, the number of passes when digging and, accordingly, the digging time are also maximized. The part of the fuel required to turns is in the second place. Despite the fact that the turns occur at the minimal resistance, the number of passes is added up, as illustrated in formula (5). When moving soil, the fuel consumption is in the third place, as the resistance 
when moving the soil is less than that when digging the soil, the grader is operating at a lower traction power, the fuel consumed by the engine is reduced. The number of passes is also less. And the last place is occupied by the consumption of fuel at the finishing operations, as the resistance is not great and the number of passes is less.

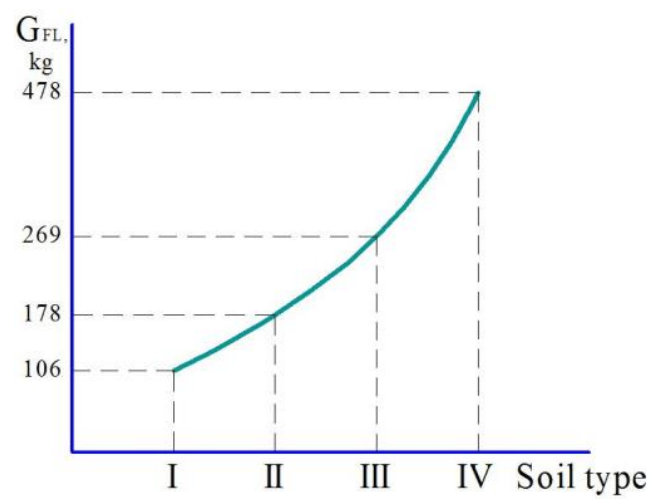

Fig. 1. The effect of soil category on the fuel consumed by the motor grader when constructing the subgrade section.

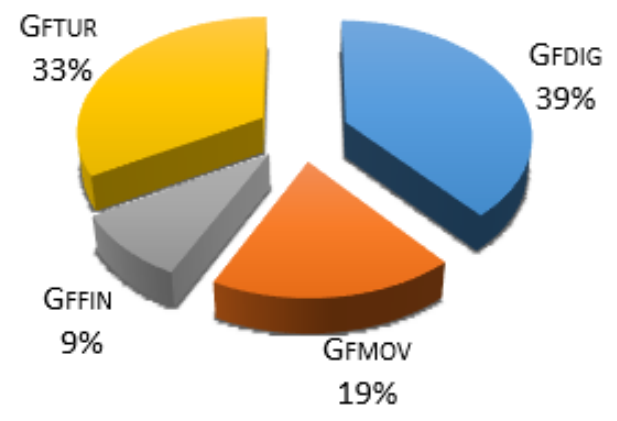

Fig. 2. The components of the road grader fuel consumption from formula (1).

According to formulas (13)...(20), it is possible to determine the components of the fuel balance and to analyze the results. For example, Fig. 3 shows the grader fuel balance when digging soil.

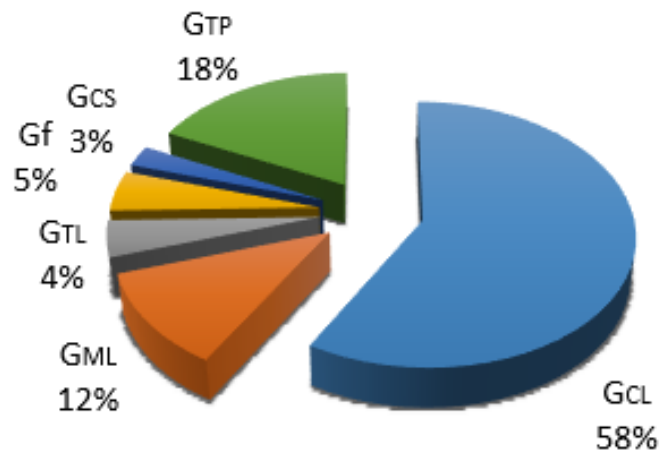

Fig. 3. The road grader fuel balance when digging soil. 
Consider the losses in the motor. The amount of the fuel consumed by the motor heat losses GCL as a percentage of the fuel consumption is $58 \%$, and by the mechanical losses $12 \%$.

The amount of the fuel consumed by the lost power in the transmission GTL is $4 \%$.

Consider the loss in the wheel mover. The amount of the fuel consumed by overcoming rolling resistance $\mathrm{Gf}$ is $5 \%$, by the slipping of the wheel mover GCS $-3 \%$.

The amount of the fuel consumed by getting the traction power GTR is $18 \%$.

\section{Conclusions}

By the example of the road grader, the technique of the analytical determination of the EMM fuel consumption when performing the technological operations is presented. Taking into account the characteristics of the work of the other EMM, the use of this method will make it possible to determine the fuel consumption of machines such as bulldozers, scrapers, grader-elevators when performing the technological operations.

The example of defining the fuel balance of the DZ-122 motor grader with the analysis of its components when it digs soil has been considered.

The results of calculating the fuel consumption for the technological operations of the grader and the components of the fuel balance when digging soil have been analyzed.

It is proposed to use the fuel balance to determine the specific design measures aimed at reducing all kinds of the EMM losses and reducing the fuel consumption, respectively.

\section{References}

1. S.G. Thorpe, Fuel economy standards, new vehicle sales, and average fuel efficiency. Journal of regulatory economics. Vol. 11, No 3. p. 311-326. (1997)

2. S.E. Plotkin, D.L. Greene, Prospects for improving the fuel economy of light-duty vehicles. Energy policy. Vol. 25, No 14-15 p. 1179-1188. (1997)

3. M. Corso, M. Muffatto, R. Verganti, Reusability and multi-product development policies: a comparison of approaches in the automotive, motorcycle and earh-moving machinery industries. Robotics and computer-integrated manufacturing. Vol. 15, p. 155-165. (1999)

4. M. Yun John, Offsetting behavior effects of the corporate average fuel economy standards. Vol. 40, No 2 p. 260. (2002)

5. A.P. Kryuchin, Performance characteristics and efficiency of earth-moving machines. Moscow: Transport; (1975)

6. N.I. Govorushenko, Fuel saving and toxicity reduction in road transport. Moscow: Transport. (1990)

7. Earthmover. American city \& country. Vol. 114, No 14 p. 15. (1999)

8. Plotkin S.E. Automobile fuel economy: how far should we go? Environment. Vol. 35, No 3 p. 25-29. (1993)

9. N.A. Ulyanov, E.G. Roninson, V.G. Soloviev. Self-propelled wheeled earth-moving machines. Moscow: Mashinostroenie; (1976)

10. N.A. Ulyanov, The theory of self-propelled wheeled earth-moving machinery. Moscow: Mashinostroenie; (1969)

11. N.A. Ulyanov, Fundamentals of theory and calculation of wheel mover machinery. Moscow: Mashgiz; (1962) 
12. A.M. Kholodov, V.V. Nitschke, L.V. Nazarov Earth-moving machinery. Kharkov: Vyscha Shkola; (1982)

13. V.L. Tyunin, Methods of calculation of power factors of the wheel mover earth-moving machines: dis. Cand. tech. Sciences. Voronezh: VGASU; (2008)

14. V.A. July, V.L. Tyunin, Power and fuel balances of wheeled earth-moving machines. Construction and road machines. No. 9. p. 42-45. (2014)

15. V.A. July, V.L. Tyunin, A.V. Krestnikov, Assessment of fuel economy self-propelled wheeled earth-moving machinery. Mechanization of construction. Vol. 77. No. 8. p. 27-31. (2016)

16. I.M. Lenin, Car and tractor engines. Part 1. Moscow: Higher school; (1976)

17. V.I. Syurkin, Fundamentals of theory and design of automotive engines. SPb, Moscow, Krasnodar: LAN; (2013)

18. A.I. Kolchin, V.P. Demidov, Calculation of automobile and tractor engines. Moscow: High school. (2002)

19. A.A. Tokarev, Theoretical background the design analysis of power, power and fuel balance auto. Proc. NAMI, the Improvement of the technical and economic performance of automotive vehicles. p. 40-45. (1989) 